\title{
EL BIEN COMÚN POLÍTICO
}

\section{The political common good}

Il bene comune politico

Carlos Alberto Gabriel Maino ${ }^{1}$

Para citar este artículo:

Maino. C.A.G. (2020). "El bien común político". Prudentia Iuris, N. Aniversario, pp. 133-147.

DOI: https://doi.org/10.46553/prudentia.aniversario.2020.pp.133-147

Resumen: El artículo aborda el problema del bien común político y la importancia del respeto a la familia y al resto de las sociedades infrapolíticas, de acuerdo con el orden natural y el principio de subsidiariedad, tomando como fuente principal las ideas del profesor Bernardino Montejano, y otros autores de la tradición clásica de nuestra Facultad de Derecho de la UCA.

Palabras clave: Bien común; Principio de subsidiariedad; Derecho Natural; Sociedades infrapolíticas; Sociedades intermedias; Familia.

Abstract: The article addresses the problem of the common good in the political society and the respect for the family and the rest of infrapolitical societies, in accordance with the natural law and the principle of subsidiarity. The ideas of Professor Bernardino Montejano, and others authors of the classical tradition of UCA Law School, are taken as main source.

Keywords: Common good; Principle of subsidiarity; Natural Law; Infrapolitical societies; Intermediate societies; Family.

1 Profesor Titular con dedicación especial, Universidad Católica Argentina, Buenos Aires, Argentina. Profesor adjunto regular, Universidad de Buenos Aires, Buenos Aires, Argentina. Correo electrónico: gabrielmaino@uca.edu.ar. 
Sommario: L'articolo affronta il problema del bene comune politico e l'importanza del rispetto per la famiglia e l'altre società infrapolitiche, in conformità con l'ordine naturale e il principio di sussidiarietà. Si prende come fonte principale le opere del professore Bernardino Montejano e altri autori della tradizione classica della nostra Facoltá di Diritto dell'UCA.

Parole chiave: Bene comune; Principio di sussidiarietà; Legge Naturale; Società infrapolitiche; Società intermedie; Famiglia.

\section{Introducción}

Cada cierto tiempo, motivado a veces por cuestiones coyunturales, resurge la pregunta por el bien común político. Este es un concepto político y jurídico básico de la tradición occidental que permite ordenar las leyes, distinguir la justicia de la injusticia y orientar la prudencia política de los gobernantes.

Las situaciones que exigen a los ciudadanos una mayor erogación de la habitual a la comunidad, como puede ser una guerra, una gran conmoción interna, una peste o alguna otra calamidad provocada por el hombre o por las fuerzas de la naturaleza, patentizan lo que está presente en toda comunidad política: la prosecución del bien común y la obligación política de los ciudadanos que ello implica.

Al mismo tiempo, en la modernidad, la idea de bien común ha sido tergiversada por las ideologías de distinto signo, y se la ha confundido ora con el interés del Estado, ora con la sumatoria de bienes particulares, ora con intereses sectoriales, partidistas o clasistas.

El objetivo de este trabajo es el esclarecimiento académico de esta noción utilizando como fuente principal una obra de uno de los profesores de Filosofía del Derecho eminentes que ha tenido la Facultad de Derecho de la UCA. Me refiero a la tesis doctoral del profesor Bernardino Montejano (h), escrita con la dirección de quien fuera Decano de esta misma Facultad, el Dr. Alfredo Di Pietro. El trabajo fue publicado con el título Ideología, Racionalismo y Realidad $^{2}$. Se trata de una obra de un extraordinario valor científico y de gran actualidad en la que se desarrolla -entre otros- el tema que nos ocupa, realizando las distinciones que exige nuestro tiempo y analizando cómo las ideologías afectaron la vida política y jurídica occidental.

2 Montejano, B. (1981). Ideología, Racionalismo y Realidad. Buenos Aires. Abeledo Perrot. 


\section{La centralidad en el ser humano}

En el ámbito político y jurídico hodierno existe una gran impulsividad en la definición de conceptos y cursos de acción. La comunicación de los medios masivos y las redes sociales generan reacciones inmediatas y lábiles en gobernantes y gobernados. Esta característica de nuestro tiempo nos ubica en las antípodas de la prudencia, la virtud propia del gobierno, sin la cual es imposible alcanzar el bien común político ${ }^{3}$. Lo mismo ocurre en el ámbito jurídico, donde lo políticamente correcto pareciera muchas veces primar sobre un razonamiento realista y orientado a la justicia, tanto en elaboraciones doctrinarias como en decisiones judiciales ${ }^{4}$.

Pero si para alcanzar el bien común político se requiere de la prudencia, comprender esta virtud cardinal requiere partir de una noción desideologizada de la persona humana. El hombre es un ser de peculiares características que requiere para su desarrollo la interacción en diversas formas de sociedad. Solo partiendo de una noción realista de lo que el ser humano es podremos comprender cómo debe actuar tanto individual como socialmente ${ }^{5}$.

En nuestra tradición tiene especial importancia la clásica definición boeciana sustancia individual de naturaleza racional a la que, para una mejor comprensión de la realidad de la persona humana, debemos adicionar su dimensión corporal. En efecto, hombre es una realidad material animada que recibe su forma del alma racional. Esta racionalidad lo vuelve único entre el resto de los animales, es una racionalidad encarnada en nuestra animalidad. Y esa racionalidad -la inteligencia y la voluntad- es lo que distingue al ser humano ${ }^{6}$.

Ahora bien, que el hombre sea sustancia, es decir, que exista en sí, no significa que exista por sí. Junto con su ser debemos afirmar la imperfección de su ser, siendo su naturaleza la de un ser creado que tiene un fin a alcanzar -el Creador- a través de su accionar. El hombre goza de una libertad situada, y sus actos inteligentes y voluntarios le permiten reafirmar su ser hacia la plena realización cuando son rectos, o deshumanizarse cuando son desordenados 7 .

3 De Aquino, S. T. S. Th. II-II, q. 47, a 10.

4 Cfr. Madrid, R. (2014). "Derecho, Derecho Natural y el concepto de lo políticamente correcto”. En Derecho Natural y Iusnaturalismos, Chávez-Fernández Postigo, J. y Santa María D’Angelo, R. (coords.). Lima. Palestra, 235.

5 Cfr. Montejano, B. (1981). Ob. cit., 17.

6 Cfr. ibídem, 19.

7 Cfr. ibídem, 20. 
Además de la racionalidad, corporeidad, libertad, fin trascendente, encontramos en la naturaleza humana la sociabilidad. El hombre necesita para su despliegue una serie de bienes o perfecciones que son imposibles de alcanzar sin los otros. La realización plena de la persona requiere de las distintas realidades asociativas: la familia, las sociedades intermedias y la sociedad política, que hoy llamamos Estado. El ser humano solo puede alcanzar la felicidad y una existencia plena merced a esta vida social, que le provee la educación, la cultura, los bienes materiales, la división del trabajo $^{8}$.

\section{Las sociedades infrapolíticas}

Los distintos tipos de sociedad son una realidad accidental que se inhiere en la sustancia que es el ser humano. Siguiendo la clasificación clásica, se trata del accidente de relación, pues implica un todo relacional o un plexo de relaciones sociales, como afirma Julio Guido Soaje Ramos. Y dichas relaciones se ordenan a realizar algo en común: este fin que persigue la praxis social ha de ser el bien común. Este querer común es fundamental para comprender a una sociedad porque es su elemento formal constitutivo. De esta manera, nos separamos tanto del sociologismo o colectivismo que pretende darle a la sociedad una entidad sustancial de la cual cada uno de nosotros es un producto, como también del individualismo que disuelve a la sociedad en una mera y disgregada sumatoria de individuos ${ }^{9}$.

La versión contemporánea del colectivismo es el estatismo vinculado a la filosofía llamada neomarxista, que perpetua la dinámica del conflicto y el materialismo en todos los aspectos de la vida, incluso en la persona humana consigo misma y en sus relaciones familiares más íntimas. El poder se concentra en quienes detentan el control del Estado; desaparece el bien común, que resulta suplantado por el bien del Estado, el que se confunde con el bien particular de quienes gobiernan o de los grupos a los que estos responden. Desaparecidas o debilitadas las sociedades infrapolíticas, el Estado comienza a ocupar su lugar en todos los aspectos de la vida social: la educación, la cultura, la producción, el comercio, incluso hasta las prácticas religiosas son susceptibles de regulación y apropiación por parte del Leviathan.

Igual de monstruoso es el resultado del individualismo alternativo, e idéntica soledad experimenta el ciudadano en la selva de intereses particulares en que queda inmerso, sin la contención y promoción personal que

8 Cfr. ibídem, 24.

9 Cfr. ibídem, 30. 
se alcanza en las sociedades infrapolíticas. En este otro extremo, el bien común resulta suplantado por la sumatoria de intereses individuales. No hay articulación, ni gradualismo, ni jerarquía, y en tal disgregación termina nuevamente imponiéndose el más fuerte en detrimento de la sociedad política y su unidad.

Ambos vicios extremos son las dos caras de una misma moneda, forjada en el inmanentismo y el materialismo, propios del árido páramo de la modernidad fecunda en desarrollo tecnológico pero plagada de miseria, hacinamiento, utopías, esclavitudes, guerras y totalitarismos. Frente a este panorama, que ya es ancestral para cualquier millennial, no es sorprendente el nihilismo consumista de esta posmodernidad. Todos nosotros, hombres de este tiempo, debemos ser conscientes de nuestro propio desconcierto; del cual solo se sale por arriba ${ }^{10}$.

Estas concepciones erradas del Estado destruyen la vida social, la ahogan a través de su burocracia y su invencible poder, acrecentado cada vez más por el desarrollo tecnológico. Socavan la responsabilidad e iniciativa personal de los ciudadanos y eliminan la sana diversidad de fines sociales de las sociedades infrapolíticas. En efecto, el concepto de sociedad abarca una pluralidad de sociedades en las que se concreta la naturaleza social humana. Una de ellas es la sociedad política, pero nuestra sociabilidad no se reduce a ella. Por lo contrario, nos insertamos en la vida social a partir de sociedades intermedias o infrapolíticas, entre las cuales la primera es la familia ${ }^{11}$.

La primacía de la familia está ya reconocida por Aristóteles, aunque no concibe a la familia como la entiende el mundo moderno; habla más bien de oikía u oikos, es decir, casa, que los latinos vertían por domus o familia doméstica. Pues oikía significa no tanto el edificio en que se habita cuanto el conjunto de hombres y de bienes que lo integran: "Primero y ante todo, casa, mujer y buey de labranza [...] la comunidad constituida naturalmente para la vida cotidiana es la casa [...] los que comparten harina y pan [...] los que comparten la mesa"12. Es pertinente señalar que para el Estagirita, la vida familiar no es una elección sino una necesidad: el matrimonio es un medio de lograr la perduración de la especie humana ${ }^{13}$. Lo propio del hombre es la razón, conforme a la cual le conviene obrar por discernimiento y elección. Pero también hay algo en el hombre que le es común con otros seres, a saber, el engendrar. Esto no compete al hombre por elección, o sea, por medio de una razón electiva, sino por un modo de adecuación que le es común con los

10 Cfr. Marechal, L. (1936). Laberinto de amor. Buenos Aires. Editorial Sur.

11 Cfr. Montejano, B. (1981). Ob. cit., 31.

12 Cfr. Aristóteles. Política, 1252b, 10.

13 Cfr. ibídem, 1252a, 26-29. 
animales y los otros seres vivos. Pues en todos existe un apetito natural que los mueve a dejar tras de sí un individuo semejante a ellos mismos ${ }^{14}$. No obstante, lo único que dice aquí es que la generación es origen, pero no fin exclusivo del matrimonio: en este busca el hombre también una perfección interna individual ${ }^{15}$.

Todas y cada una de las sociedades infrapoliticas tienen un fin, un bien común propio y relativa autonomía, y fortalecen la existencia de los hombres, llenándola de vida. Su debilitamiento y persecución implican el aniquilamiento del hombre mismo y de la posibilidad de su felicidad y realización. Tanto el individualismo liberal como el estatismo neomarxista destruyen los vínculos sociales dejando al individuo sólo y asilado frente a los grupos de poder o frente al Estado planificador. Se borran así los bienes comunes y valores que enriquecen la vida social y se articulan en el bien común político propio de la sociedad política, esta sí autónoma y -por eso- perfecta.

La sociedad política resulta entonces una sociedad de sociedades y la relación de las sociedades infrapolíticas con el Estado no es siempre pacífica, puede haber tensiones y entrecruzamiento de fidelidades y competencias que deben ser resueltas sobre la base de la justicia, la cooperación y la subsidiariedad.

De la primera y fundamental sociedad infrapolítica que es la familia surgen sociedades que la complementan, como la escuela, la universidad, la empresa, las asociaciones de profesionales y trabajadores, las asociaciones sin fines de lucro, para llegar al municipio, y a la principal de nuestro orden constitucional: la provincia ${ }^{16}$.

Por ello, Montejano sostiene que una verdadera renovación de la sociedad debe realizarse de abajo hacia arriba, comenzando por la familia, y luego las relaciones locales, pues es la inmediatez de los grupos infrapolíticos la que permite el natural desarrollo de las virtudes sociales fundamentales. De esta forma se evitan a un mismo tiempo la soledad del ciudadano frente al Estado y el degeneramiento burocrático de este ${ }^{17}$.

Esta renovación de la sociedad política implica que nuestro orden jurídico reconozca a las sociedades infrapolíticas y les otorgue el lugar que les corresponde en la vida social. Ello exige necesariamente el fortalecimiento del federalismo y la efectiva vigencia del principio de subsidiariedad. Finalmente, a pesar de su autonomía y perfección, aún la sociedad política debe estar abierta a encontrar una última complementación en la sociedad

14 Cfr. Cruz Cruz, J. Familia, trabajo y política en Aristóteles. Universidad de Navarra, recuperado de: https://core.ac.uk/download/pdf/83564466.pdf

15 Cfr. Aristóteles. Ética a Nicómaco, 1162 a.

16 Cfr. Montejano, B. (1981). Ob. cit., 34.

17 Cfr. ibídem, 36. 
internacional, no para someterse a un nuevo orden mundial, sino para que reine la concordia y la cooperación entre los pueblos.

\section{La política, la ética y el principio de subsidiariedad}

La política es una actividad humana, entendiendo por tal aquella que se hace con conocimiento del fin que se persigue y eligiendo de un modo libre los medios para lograrlo. En el caso de la política, el fin es el bien común político, y este constituye su primer principio normativo y criterio de justicia.

En efecto, dado que la política es una actividad propia del obrar humano, se encuentra incardinada en la ética. Es decir, la praxis política se encuentra sujeta a normas que prescriben qué debe hacerse y qué debe evitarse para alcanzar su fin. Dicho fin, el bien común político, es el buen vivir o la vida buena, que tiene una dimensión ética fundamental, sin perjuicio de otros aspectos vinculados al bienestar y el desarrollo, todos orientados al florecimiento de las potencialidades del hombre ${ }^{18}$. Así, debemos volver a la centralidad del ser humano como la clave de bóveda que permite una comprensión adecuada de lo que el bien común político es.

En efecto, al ser el hombre un ser que vive en sociedad y es libre, necesita lo que en la tradición griega se denomina nomos, que ordena la convivencia y hace viable la vida. Pero esta viabilidad no apunta solo a la seguridad de individuos libertinos regulados mediante un contrato ficticio, sino de un orden que permite y favorece la perfección de la vida humana, y ayuda al hombre a ordenarse interiormente y lo dispone a practicar la justicia y la amistad.

El ser humano necesita principios que regulen su actividad. En el campo práctico, lo primero aprehendido por la razón orientada a la praxis es el bien, porque todo agente obra por un fin que tiene razón de bien. Este, pues, será el primer principio del obrar humano: se debe hacer el bien y evitar hacer el mal. Como afirma Montejano, este es el punto de partida evidente de conocimiento práctico, y como previniéndonos anticipadamente del nihilismo jurídico propio del abolicionismo penal, advierte que no "tendrían sentido las nociones de responsabilidad, premio y castigo, si se negara la posibilidad del discernimiento de lo bueno y de lo malo y la libertad de actuar consiguiente"19. En efecto, la posibilidad de discernir los principios, de conocer los fines y de actuar en consecuencia distinguiendo lo bueno de lo

18 Cfr. ibídem, 54.

19 Cfr. ibídem, 61. 
malo tiene una concreción normativa en la ley natural, cuyo primer precepto es justamente este: se debe hacer el bien y evitar el mal ${ }^{20}$.

Ahora bien, "el concepto de bien abarca el de bien común. Y el de bien común, el de bien común político, fin del Derecho y de la sociedad política. Este bien común político es un bien común concreto, que se alcanza a través de una conducta ajustada a normas concretas, cuyos contenidos se encuentran parcialmente constituidos por exigencias que surgen de la naturaleza y parcialmente por determinaciones efectuadas por la autoridad (determinación legal o jurisdiccional), por la comunidad (determinación consuetudinaria) o por los interesados o sus representantes grupales (determinación autónoma)"21.

La naturaleza es, entonces, el origen de los principios que regulan la actividad política, y su fundamento está en los fines perfectivos connaturales del ser humano y en las tendencias inscriptas en su naturaleza que lo orientan hacia tales fines. Las primeras de tales inclinaciones son la conservación de su ser, conforme a su propia naturaleza, la comunicación sexual procreativa, y conocer la verdad natural y sobrenatural y vivir en sociedad.

El bien común político consiste en bienes necesarios para que los ciudadanos alcancen estos fines perfectivos de acuerdo con las exigencias de la naturaleza humana. Además, debe tener en cuenta que el bien común político no es el último y más importante de los bienes comunes: este es el bien común trascendente. La política, como ordenadora de la comunidad, debe tener en cuenta esta realidad antropológica para lograr un orden social justo. Si ello no ocurre, el jurista debe buscar los medios adecuados para descalificar las normas o decisiones injustas, y en casos extremos los ciudadanos deberán considerar la desobediencia, como ha señalado incluso Santo Tomás de Aquino 22 .

Así, el bien común político constituye el primer principio normativo y criterio de justicia de la vida social; el segundo -subordinado a este- es el principio de subsidiariedad.

Como ya hemos desarrollado, la sociedad política no es una yuxtaposición masificada de individuos sino una sociedad de sociedades infrapoliticas, que tienen sus propios fines y bienes comunes que se articulan orgánicamente en el bien común político. Al tener los individuos y las sociedades infrapolíticas sus fines propios deben tener la libertad suficiente para poder alcanzarlos. Lo opuesto es el totalitarismo estatista o individualista.

20 Aquino, S.T. S. Th. I-II, q. 94, a. 2.

21 Montejano, B. (1981). Ob. cit., 62.

22 Cfr. De Aquino, S. T. S. Th., I-II, 96, 4, c. 
De ello se desprende que el Estado debe respetar a las sociedades infrapolíticas, a todas ellas, pero en especial a la familia. En efecto, el fin del Estado es alcanzar el orden y la paz, y dicho fin solo se alcanza cuando el Estado se encuentra al servicio de la familia, respetando el orden natural, no cuando la manipula llevando adelante experimentos sociales. El Estado debe crear las condiciones favorables que hagan posible el desarrollo de la vida familiar: "Y no hay vida familiar posible sin un ámbito físico decoroso que permita lenta y pacientemente establecer lazos profundos y duraderos, que resistan la erosión del tiempo y las presiones e influencias exteriores de la sociedad de masas" 23 .

En forma análoga deben respetarse el resto de las sociedades intermedias, las relacionadas con la educación, con la producción y el trabajo, con el culto a Dios. Este principio de discreción y reserva en toda la actividad de los órganos superiores respecto de los de inferior jerarquía y comprensión es un criterio de buen gobierno ${ }^{24}$. Es, además, el principio que gobierna el federalismo que sólo pone en cabeza del Estado federal aquellas competencias que por su naturaleza no pueden ser alcanzadas por las provincias $u$ otras sociedades infrapolíticas menores, sin que por ello se menoscabe la unidad de la nación. No es ocioso tener en cuenta que la tradición jurídica latinoamericana tiene a este principio como uno de sus fundamentales, al punto de que es reconocido en varias Constituciones del continente ${ }^{25}$.

Pero el principio de subsidiariedad no es solo libertad o restricción, sino que cuando es conveniente que una actividad esté a cargo del Estado

23 Montejano, B. (1986). Familia y Nación histórica. Buenos Aires. Ediciones del Cruzamante, 34 .

24 Santo Tomás de Aquino manifestó: “[...] una exagerada unificación y uniformidad amenazan la existencia de una sociedad compuesta por muchas estructuras, como cuando desaparecen la sinfonía y la armonía de las voces si todos cantan en el mismo tono". Cfr. Comentario a La Política de Aristóteles, 11, 5.

25 Sería un error atribuir el principio sólo al pensamiento de la Doctrina Social de la Iglesia, aunque es insoslayable mencionar que esta doctrina recoge el principio de manera reiterada en diversos documentos. Sólo a guisa de ejemplo transcribiré la carta encíclica Mater et Magistra para mostrar que no es sólo la Rerum Novarum o la Centesimus Annus las que aluden al principio, sino que hace más de cien años que la Iglesia viene diciendo lo mismo, con distinto énfasis según las circunstancias. "Así como no es lícito quitar a los individuos y traspasar a la comunidad lo que ellos pueden realizar con su propio esfuerzo e iniciativa, así tampoco es justo, porque daña y perturba gravemente el recto orden social, atribuir a una sociedad mayor y más elevada lo que las comunidades menores inferiores pueden hacer y ofrecer por sí mismas, ya que toda acción de la sociedad en virtud de su propia naturaleza debe prestar ayuda a los miembros del cuerpo social pero nunca destruirlos ni absorberlos”. En el mundo anglosajón el principio es conocido como propio del pensamiento católico, pero no ocurre lo mismo en Europa. En Alemania, el principio es considerando como un übrigens deutsch-rechtlichen Grundsatz (principio máximo legal alemán). 
por razones de bien común político o cuando es necesario su apoyo para realizar determinadas tareas, aparece la función subsidiaria en su faz positiva $^{26}$. Los límites de unas sociedades y otras están dados en ellas mismas y son señalados por los fines a los que cada una tiende y las tareas que les son reservadas ${ }^{27}$.

La negación del principio de subsidiariedad es la negación de las sociedades infrapolíticas y, la negación de estas, es la negación de la sociabilidad natural del hombre, de esa inclinación a vivir en sociedad y del desarrollo de la virtud y otros aspectos de la educación moral que solo se logran en ellas. Implica una deshumanización de la existencia en el anonimato de la masa controlada por los poderosos a través del Estado y los medios de comunicación.

\section{El bien común político y el bien individual}

Llegados a este punto conviene ofrecer una definición de bien común. Se lo ha definido como la paz y la seguridad de las cuales las familias y cada uno de los individuos puedan disfrutar en el ejercicio de sus derechos, y al mismo tiempo en la mayor abundancia de bienes espirituales y temporales que sea posible mediante la concorde colaboración activa de todos los ciudadanos ${ }^{28}$.

El bien común político es una necesidad para la persona, que no puede desarrollar sus fines en el orden espiritual y temporal sin participar de él. $\mathrm{Al}$ ser un bien concreto, estamos en el campo de lo posible y de lo que las circunstancias permiten al accionar humano. Aunque esencialmente esté fundado en la naturaleza humana, sucede con él lo mismo que con el Derecho, en el que su determinación debe conformarse a las circunstancias históricas de cada sociedad política concreta, y responder a su genio y a sus exigencias inmediatas ${ }^{29}$. De modo que el bien común, idéntico en sus fundamentos, varía en cada Estado de que se trate ${ }^{30}$.

$\mathrm{Al}$ ser una necesidad, no se puede prescindir de él, ni tampoco de los deberes que nos impone la colaboración activa de todos los miembros de la

26 Cfr. Montejano, B. (1981), 66.

27 Cfr. Graneris, G. (1973). Contribución tomista a la Filosofía del Derecho. Buenos Aries. Eudeba, 149.

28 Pío XI, PP. (1929). Divini illus magistri, 36.

29 Cfr. Puy, F. (1998). "El Derecho, la justicia y la ley nacen de fuentes locales". En La historia de la filosofía jurídica española. Coord. Francisco Puy y Salvador Rus. Santiago de Compostela. Fundación Alfredo Brañas.

30 Cfr. Sampay, A. E. (1951). Introducción a la Teoría del Estado. Buenos Aires. Politeia, 419 . 
sociedad política; a su vez, ordenados por el Derecho y la ley natural. Su resultado en la vida humana es la paz y la seguridad de las familias y las otras sociedades infrapolíticas en el ejercicio de sus derechos y la mayor abundancia de bienes espirituales y temporales alcanzados ${ }^{31}$.

Se trata de un bien indivisiblemente participable. En efecto, si pudiera ser dividido y repartido, perdería su condición de común ${ }^{32}$. El bien común se comunica a cada uno de los miembros de la sociedad "como el ser a sus modos particulares, como la salud y el bienestar del organismo a todos sus miembros, como la virtud vivificante del alma a todas la partes del cuerpo"33.

Además, el bien común político tiene un carácter esencialmente dinámico, en el sentido de que no es algo que se posee, sino un bien que todos contribuyen a realizar cotidianamente con la coordinación del Estado, y del cual todos participan y disfrutan en común ${ }^{34}$. Este dinamismo también se origina en el hecho de que el orden justo que el bien común político representa nunca podrá ser alcanzado de un modo definitivo, porque no son estables las circunstancias concretas en que ha de darse, y tampoco es estable la disposición virtuosa de las personas, habida cuenta de que el hombre es naturaleza caída ${ }^{35}$.

Son ejemplos del bien común político la justicia, la paz, el orden, la seguridad, la ciencia. Por ello, no puede oponerse el bien común político al bien individual. Al contrario, ambos bienes no sólo no se excluyen, sino que se exigen mutuamente, pues sin el disfrute de bienes particulares el bien común sería irrealizable y, viceversa, la no realización del bien común torna imposible la del bien individual. Ciertamente, es condición para alcanzar la justicia tener satisfechas las necesidades básicas de los individuos, y al mismo tiempo, en una sociedad sin justicia, es imposible satisfacer dichas necesidades básicas.

Esta interdependencia tiene su razón en que el bien personal se compone de bienes tanto de naturaleza individual como común. Unos y otros son indispensables para el desarrollo armónico y logrado de la persona humana, tanto el alimento y el vestido, como la verdad y la justicia. De todos modos,

31 Cfr. Montejano, B. (1981), 64.

32 Cfr. Casares T. D. "Notas sobre justicia y bien común”. En AA. VV. (1978). Acerca de la Justicia. Buenos Aires, Abeledo Perrot, 13.

33 Cfr. Portela, J. G. (2008). Una introducción a los valores jurídicos. Santa Fe. Rubinzal-Culzoni, 88.

34 Cfr. Sacheri, C. A. (1980). El orden natural. Buenos Aires. Ediciones del Cruzamante, 151.

35 Cfr. Casares, T. D. (1978). Ob. cit., 14. 
esta interdependencia no excluye la jerarquía, porque el bien común político es superior al resto de los bienes comunes y al bien individual ${ }^{36}$.

La jerarquía del bien común político sobre el resto de los bienes mencionados se desprende de que (a) en toda existencia individual solo es posible en sociedad y ningún bien particular podría alcanzarse fuera de la sociedad política; (b) pero además, habida cuenta de la naturaleza social de la persona, es desordenada una apetencia al bien individual desatendida de la obtención del bien participable con quienes convive; y finalmente (c) en que el bien individual se consuma en la virtud, y el bien común la promueve ${ }^{37}$.

Sería un error concebir a los particulares como acreedores de bienes particulares o al gobernante como su deudor; sí -en cambio- el gobernante es deudor del orden justo en la participación de los bienes que la vida social comporta. De modo análogo, los individuos deben a la sociedad política contribuciones y servicios particulares, pero a título de contribución al bien común, es decir, lo que propiamente se debe es una disposición a la obediencia al orden de la sociedad política ${ }^{38}$.

\section{Epílogo}

El bien común político, por ser el que permite el perfeccionamiento de las potencialidades de los hombres y le permite alcanzar bienes de los que por su índole no podrían participar de otro modo, resulta ser amado por ellos; y crea entre ellos también una comunión vital afectiva llamada amistad política ${ }^{39}$. Dicha amistad es el amor mutuo fundado en la comunidad de objetos amados, lo que constituye un pueblo ${ }^{40}$.

La sociedad política es la más perfecta de las sociedades humanas, por lo tanto, la amistad política constituye un amor superior al que nace de las sociedades infrapolíticas, incluso del amor familiar. De allí que el amor a la Patria sea el mayor entre los amores temporales, por debajo del amor a Dios, que es el mayor y más perfecto, por ser Dios causa eficiente, ejemplar y final del ser humano, y destino de todos los hombres. En otras palabras, la jerarquía de bienes determina una jerarquía de amores, del que muchos mártires cristianos han dado testimonio a lo largo de los siglos.

En el tiempo presente, signado por la epidemia de COVID-19, de características imprecisas que aún no podemos develar completamente, se ha

36 Cfr. Sacheri, C. A. (1980). Ob. cit., 151.

37 Cfr. Casares, T. D. (1978). Ob. cit., 13.

38 Cfr. ibídem, 14.

39 Cfr. Sampay A. E. (1951). Ibídem.

40 De Hipona, S. A. Civitate Dei, XX, 24. 
puesto nuevamente en el tapete el problema del bien común político y las erogaciones que este puede demandar a los ciudadanos y el cercenamiento legítimo o ilegítimo de su libertad. También surgen cuestiones relacionadas con la economía y la paz social, dado que el asilamiento elegido para enfrentar la epidemia pone en peligro la funcionalidad de los sectores productivos y económicos, lo que ocasionará quiebras, desempleo, más pobreza y conflictos sociales.

Asimismo, la situación nos interpela acerca del bien común político internacional, la soberanía nacional, la utilidad de los organismos supranacionales y la globalización "para la que todo el planeta es un 'sistema' de conexiones y encajes rígidos, una construcción artificial gobernada por los expertos, una serie de vasos comunicantes aparentemente sólidos. Sin embargo, esta concepción ha demostrado ser débil porque ha bastado que el sistema haya sido atacado en un punto para crear un efecto dominó que se ha propagado con gran celeridad. Una epidemia puede causar la crisis del sistema sanitario; las cuarentenas causan la crisis del sistema de producción, lo que, a su vez, hace que se derrumbe el sistema económico; la pobreza y el paro dejan de alimentar el sistema del crédito; el debilitamiento de la población la expone a nuevas epidemias y, de nuevo, vuelta a empezar en una serie de círculos viciosos a nivel planetario. La globalización presentaba hasta ayer la magnificencia y la gloria de su perfecto funcionamiento técnico-funcional, desdeñando con un engreimiento indiscutible la obsolescencia de los Estados y las naciones, y resaltando el valor absoluto de la 'sociedad abierta': un solo mundo, una sola religión, una sola moral universal, un solo pueblo mundialista, una sola autoridad mundial. Ha bastado un virus para que todo el sistema se derrumbe, dado que los niveles no globales de las respuestas han sido inhabilitados. La experiencia que estamos viviendo nos pone en guardia sobre una 'sociedad abierta' entendida de este modo, ya sea porque se pone en las manos del poder de pocos, o porque unas pocas manos podrían hacerla caer como un castillo de naipes. Esto no significa que hay que negar la importancia de la colaboración internacional que, precisamente, exigen las pandemias; sin embargo, dicha colaboración no tiene nada que ver con estructuras colectivas, mecánicas, automáticas y globalmente sistémicas" 41 .

Finalmente, se nos plantea el problema de la relación del bien común político con la Religión Católica y otras confesiones. La prohibición del culto

41 Crepaldi, G. (2020). "Coronavirus, el hoy y el mañana. Reflexiones sobre una emergencia, no sólo sanitaria. Reflexión del arzobispo Giampaolo Crepaldi para el Observatorio Internacional Cardenal Van Thuân sobre la Doctrina Social de la Iglesia”, recuperado de: https://www.vanthuanobservatory.org/esp/coronavirus-el-hoy-y-el-manana-reflexiones-sobreun-emergencia-no-solo-sanitaria/. 
público a Dios y el cierre de las Iglesias puede ser lo más grave porque hace a la vida espiritual de los creyentes y a la salud del alma, pero son sólo algunos de los aspectos de este problema. Del bien común político también forma parte la salud moral del pueblo: a la razonable preocupación por evitar el contagio pareciera contraponerse la irracional despreocupación por otros aspectos del bien común político como le hemos aquí caracterizado, pues no han cesado los abortos ni el adoctrinamiento ideologizado en las escuelas, ni parece que el corrupto empobrecimiento de la población se vaya a revertir.

Salud, religión, economía, paz, ciencia, soberanía y cooperación, educación y libertad, todo forma parte del bien común político. Quiera Dios que estemos dispuestos a luchar por él haciendo los sacrificios que demande, unidos por el amor a los bienes comunes: el amor a la familia, el amor a la Patria, y, sobre todo, el amor a Dios.

\section{Bibliografía}

Aquino, S. T. S. Th. I-II, q. 94, a. 2.

Aquino, S. T. S. Th. II-II, q. 47, a 10.

Aristóteles. Ética a Nicómaco, 1162 a.

Aristóteles. Política, 1252b, 10.

Casares, T. D. "Notas sobre justicia y bien común". En AA. VV. (1978). Acerca de la Justicia. Buenos Aires. Abeledo Perrot, 13.

Crepaldi, G. (2020). "Coronavirus, el hoy y el mañana. Reflexiones sobre una emergencia, no sólo sanitaria”. Reflexión del arzobispo Giampaolo Crepaldi para el Observatorio internacional Cardenal Van Thuân sobre la Doctrina Social de la Iglesia, recuperado de: https://www.vanthuanobservatory.org/esp/coronavirus-elhoy-y-el-manana-reflexiones-sobre-un-emergencia-no-solo-sanitaria/.

Cruz Cruz, J. "Familia, trabajo y política en Aristóteles". Universidad de Navarra, recuperado de: https://core.ac.uk/download/pdf/83564466.pdf.

De Hipona, S.A. Civitate Dei, XX, 24.

Graneris, G. (1973). Contribución tomista a la Filosofía del Derecho. Buenos Aries. Eudeba, 149.

Madrid, R. (2014). "Derecho, Derecho Natural y el concepto de lo políticamente correcto”. En Derecho Natural y Iusnaturalismos. Chávez-Fernández Postigo, J. y Santa María D’Angelo, R. (coords.). Lima. Palestra, 235.

Marechal, L. (1936). Laberinto de amor. Buenos Aires. Editorial Sur.

Montejano, B. (1986). Familia y Nación histórica. Buenos Aires. Ediciones del Cruzamante, 34 .

Montejano, B. (1981). Ideología, Racionalismo y Realidad. Buenos Aires. Abeledo Perrot.

Pío XI, PP. (1929). Divini illus magistri, 36.

Portela, J. G. (2008). Una introducción a los valores jurídicos. Santa Fe. RubinzalCulzoni, 88. 


\section{EL BIEN COMÚN POLÍTICO}

Puy, F. (1998). "El Derecho, la justicia y la ley nacen de fuentes locales". En La historia de la filosofía jurídica española. Coord. Francisco Puy y Salvador Rus. Santiago de Compostela. Fundación Alfredo Brañas.

Sacheri, C. A. (1980). El orden natural. Buenos Aires. Ediciones del Cruzamante, 151.

Sampay, A. E. (1951). Introducción a la Teoría del Estado. Buenos Aires. Politeia, 419. 